\title{
Spermatogenesis, sperm output and seminal quality of Holstein bulls electroejaculated after administration of oxytocin
}

\author{
W. E. Berndtson and G. Igboeli* \\ Department of Animal and Nutritional Sciences, University of New Hampshire, Durham, \\ NH 03824, U.S.A.
}

\begin{abstract}
Summary. The 12- to 24-month-old Holstein bulls were electroejaculated twice on each of 3 days per week throughout the study. After a 2-week stabilization period and subsequent 2 -week pre-treatment period, 7 bulls were given 50 i.u. oxytocin via the jugular vein $10 \mathrm{~min}$ before each first ejaculate for 10 weeks. The 7 control bulls were handled identically but did not receive oxytocin. All bulls were castrated at the end of the study. Oxytocin was without effect on spermatogenesis $(P>0 \cdot 10)$. Oxytocin did not alter the total number of spermatozoa harvested per collection day $(P>0 \cdot 10)$, but increased the number of spermatozoa in first ejaculates by an average of $34.2 \%(P<0.025)$. Oxytocin did not affect sperm quality $(P>0 \cdot 10)$ as judged by the motility of spermatozoa in fresh semen or by the motility or percentage of spermatozoa with intact acrosomes in thawed semen. It is concluded that $50 \mathrm{i}$.u. oxytocin enhanced sperm output in first ejaculates of electroejaculated bulls without altering daily sperm production or seminal quality.
\end{abstract}

Keywords: bull; spermatogenesis; sperm output; oxytocin; semen

\section{Introduction}

Sexual preparation by 'false mounting' or active restraint of beef or dairy bulls typically results in about a $50 \%$ increase in the number of spermatozoa in first ejaculates taken with an artificial vagina (Hale \& Almquist, 1960; Almquist, 1973). Sexual preparation also induces the release of oxytocin (Sharma \& Hays, 1973) which, if injected before ejaculation into an artificial vagina, increases the sperm output of rams, bulls and rabbits (Kihlstrom \& Melin, 1963; Knight \& Lindsay, 1970; Knight, 1974a; Schefels \& ElAzab, 1975; Voglmayr, 1975; Agmo et al., 1978). Presumably, oxytocin stimulates smooth muscle contractility (Knight, 1972, 1974b), thereby enhancing sperm transport within the extragonadal ducts before and/or during ejaculation.

The collection of semen with an artificial vagina is generally preferred to collection by electroejaculation. However, electroejaculation has proved especially useful for the harvesting of semen from bulls for whom collection with an artificial vagina is precluded by inadequate libido or physical disabilities. Since electroejaculation is usually performed without sexual preparation procedures known to elicit oxytocin secretion, it seemed possible that exogenous oxytocin might enhance sperm output if given before electroejaculation. However, to be useful, oxytocin would not only need to enhance sperm output, but would need to be without adverse effects on spermatogenesis or seminal quality. The effect of chronically-administered oxytocin on bovine spermatogenesis and seminal quality is unknown. The objective of the present study was therefore to determine the effect of oxytocin, given before the electroejaculation of bulls maintained on an

\footnotetext{
*Present address: Department of Animal Science, University of Nigeria, Nsukka, Nigeria.
} 
intensive seminal collection schedule, on spermatogenesis, sperm output and seminal quality of Holstein bulls.

\section{Materials and Methods}

General. The 12- to 24-month-old Holstein bulls were housed indoors and restrained by individual neck chains. Each bull received approximately $3-4 \mathrm{~kg}$ of commercial dairy ration per day and grass hay ad libitum. Measurements of body weight and scrotal circumference were taken on Days $-28,-14,0,+14,+28,+42,+56$ and +68 , where Day 0 represents the first day of treatment. All 14 bulls were electroejaculated twice on each Monday, Wednesday and Friday for 14 weeks. An interval of 10 min was maintained between the collection of first and second ejaculates, while the order in which individual bulls were presented for collection of semen was randomized on any given day.

The first 2 weeks of the experiment served to accustom bulls to this procedure and allowed the stabilization of extragonadal sperm reserves and sperm output (Amann \& Almquist, 1961b). Data for seminal characteristics during this period were not utilized for statistical analyses. The next 2 weeks constituted a pretreatment period, which provided baseline data for the seminal characteristics of each bull. At the completion of the pretreatment period, individual bulls were placed into one of 7 groups of 2 bulls each based primarily on the similarity of sperm output. Scrotal circumference, body weight and motility of spermatozoa in fresh semen served as additional criteria for pairing, when necessary. Assignment of individual bulls to control or treated groups was conducted randomly from within each pair.

Beginning on Day 0 (the first day of the treatment period) and for the remainder of the 10-week treatment period, each treated bull was given 50 i.u. oxytocin via the jugular vein $10 \mathrm{~min}$ before the collection of each first ejaculate. Oxytocin was provided in an aqueous solution (20 i.u. $/ \mathrm{ml})$ containing chlorobutanol $(0.5 \%)$ as a preservative and acetic acid to adjust $\mathrm{pH}$. Control bulls were handled similarly and were subjected to jugular venepuncture, but did not receive oxytocin. All bulls were castrated on Day +68 .

Evaluation of seminal characteristics and quality. Insofar as possible, the pre-sperm and sperm-rich fractions of each electroejaculate were harvested separately. Immediately upon collection, both fractions were assessed for volume and sperm concentration. The latter was determined spectrophotometrically (Foote et al., 1978), except when samples were too dilute or had been contaminated with urine or other foreign matter. The sperm concentration of such samples was determined haemocytometrically. Each fresh ejaculate was also evaluated for the percentage of progressively motile spermatozoa. This measurement was taken on the sperm-rich fraction except when this sample was contaminated or otherwise inappropriate. The resulting data were used to calculate the number of spermatozoa (total and motile) per ejaculate or per day.

On Days $-5,+9,+23,+37,+51$ and +65 , semen was processed by conventional methods for freezing in $0 \cdot 5-\mathrm{ml}$ French plastic straws (DeAbreu et al., 1979). First and second ejaculates were pooled for freezing within bulls (exclusive of contaminated samples). Samples from each date were stored until the completion of the experiment, when two straws per sample were removed and thawed by immersion in $35^{\circ} \mathrm{C}$ water for $12 \mathrm{sec}$ (DeAbreu et al., 1979). The post-thaw motility of spermatozoa from each straw was assessed by each of two independent observers. Thawing and preparation of coded samples for evaluation was by a third individual. Subsequently, each thawed sample was incubated at $37^{\circ} \mathrm{C}$ for $2 \mathrm{~h}$, fixed by addition of a glutaraldehyde solution (Johnson et al., 1976) and used to determine the percentage of spermatozoa with intact acrosomes (Saacke \& Marshall, 1968). Acrosomal integrity was assessed by duplicate determinations on each sample by each of two independent evaluators without knowledge of the sample identity. All observations of post-thaw motility and acrosomal integrity for any given ejaculate were pooled within and over observers for statistical analysis.

Post-castration procedures. Immediately upon castration, each testis was weighed, the tunica albuginea was removed and weighed, and the weight of the testicular parenchyma was calculated as the difference. One slice of tissue approximately midway between the dorsal and ventral pole was placed in Zenker-formol fixative for $24 \mathrm{~h}$, washed in running tap water for $24 \mathrm{~h}$ and transferred to $70 \%$ ethanol (Berndtson \& Desjardins, 1974). Subsequently, portions of this tissue were dehydrated, embedded in paraffin wax, sectioned at $5 \mu \mathrm{m}$, stained with periodic acid-Schiff's reagent and haematoxylin and used for quantitative histometric evaluations of spermatogenesis. Additional portions of unfixed testicular parenchyma, from the middle and dorsal and ventral poles of each testis, were pooled, placed in a pre-weighed vial and stored at $-25^{\circ} \mathrm{C}$ for use in establishing testicular spermatid reserves. Each epididymis was trimmed of extraneous tissue and divided into proximal and distal segments at the mid-corpus region. Each segment was weighed, sealed in a plastic bag and stored at $-25^{\circ} \mathrm{C}$ until used to quantify epididymal sperm reserves.

Quantification of spermatogenesis from extirpated tissues. Testicular spermatid reserves were quantified by enumeration of elongated spermatids in homogenates of testicular parenchyma (Amann \& Almquist, 1961a). Daily sperm production (DSP) was calculated utilizing a time divisor of 5.32 days, which equalled the number of days of sperm production represented by homogenization-resistant elongated spermatids (Amann et al., 1974). Counts were performed in duplicate by each of two technicians. The average coefficients of variability between technicians for the DSP/g and DSP/testis of the 28 testes were $12 \cdot 6$ and $12 \cdot 7 \%$, respectively. Data for the DSP of each testis were pooled over technician and the means were used for statistical analysis.

Spermatogenesis was quantified histometrically via the direct enumeration of the nuclei of type A spermatogonia, preleptotene primary spermatocytes, pachytene primary spermatocytes and round step 8 spermatids and of Sertoli 
cell nuclei with a visible nucleolus in cross-sections of Stage VIII seminiferous tubules, as defined by Berndtson \& Desjardins (1974). For each testis, the aforementioned nuclei were counted in each of 10 seminiferous tubular crosssections by each of two evaluators ( 20 tubules per testis). The resulting crude counts were converted to true counts by application of Abercrombie's formula, whereby true count = crude count $\times$ section thickness/ (section thickness + nuclear or nucleolar diameter) (when measurements are in $\mu \mathrm{m}$ : Abercrombie, 1946; Berndtson, 1977) and for tubular shrinkage by application of a Sertoli cell correction factor (Lino, 1971; Berndtson, 1977). For the Abercrombie correction, each observer independently measured 5 nuclei of each germ cell type and 5 Sertoli cell nucleoli for each testis with an ocular micrometer, and the correction was applied on a within-testis, within-observer basis. Data were pooled over evaluators for statistical analysis. In a separate study (Berndtson et al., 1987), the average coefficients of variation between duplicate estimates of the number of germ cells per tubular cross-section, for which each estimate was based upon counts for a total of only 10 tubular cross-sections per testis (i.e. for 5 rather than 10 cross-sections per each observer), were as follows: type A spermatogonia, $9 \cdot 8 \%$; preleptotene primary spermatocytes, $4.8 \%$; pachytene primary spermatocytes, $4.8 \%$; and step 8 spermatids, $4.0 \%$

Statistical analyses. Because inherent differences in some of these measures among bulls before treatment would probably influence the results, data were handled as follows. When data sets involved repeated measurements over time (body weight, scrotal circumference, sperm motility, volume and sperm concentration of the pre-sperm and sperm-rich fractions of each ejaculate and total spermatozoa per ejaculate or per day), analyses of variance were conducted via the repeated measures design (SAS Institute, 1985) for which each seminal collection day represented a level of the time factor, with data adjusted for pre-treatment differences. The adjustment consisted of subtracting the pre-treatment mean for each measure on an individual-bull basis from each value and then addition of the grand mean for the experiment to the resulting difference (Berndtson et al., 1979). Analyses were also conducted with unadjusted data. Although the results were generally similar, all levels of statistical significance which follow are based on analyses with adjusted data, but unadjusted means are presented. Data obtained from tissues removed at castration (testicular and epididymal weights, daily sperm production (DSP) per gram of parenchyma or per testis and numbers of germ cells per seminiferous tubular cross-section) were subjected to analyses of variance as a randomized complete block design, with pair as a factor (utilizing the pairing, based on pre-treatment data, from which assignment to treatment or control groups was conducted).

\section{Results}

\section{Body weight and scrotal circumference}

Oxytocin was without effect $(P>0 \cdot 10)$ on body weight (Table 1). Bulls gained weight throughout the experiment $(P<0.005)$. The rate of gain over time, which averaged about $0.7 \mathrm{~kg}$ per day, was unaffected $(P>0 \cdot 10)$ by oxytocin administration.

Table 1. Mean \pm s.e. body weight and scrotal circumference of control and oxytocin-treated bulls

\begin{tabular}{|c|c|c|c|c|}
\hline \multirow[b]{2}{*}{ Day } & \multicolumn{2}{|c|}{ Body wt (kg) } & \multicolumn{2}{|c|}{ Scrotal circ. $(\mathrm{cm})$} \\
\hline & Control & Oxytocin & Control & Oxytocin \\
\hline-28 & $398 \pm 30$ & $392 \pm 32$ & $34 \cdot 2 \pm 1 \cdot 7$ & $32 \cdot 6 \pm 1 \cdot 1$ \\
\hline-14 & $402 \pm 32$ & $401 \pm 32$ & $34.4 \pm 1.9$ & $32.8 \pm 1.2$ \\
\hline 0 & $420 \pm 32$ & $421 \pm 32$ & $34.9 \pm 1.9$ & $33.9 \pm 1.0$ \\
\hline+14 & $431 \pm 29$ & $428 \pm 32$ & $35.0 \pm 1.8$ & $34 \cdot 1 \pm 1 \cdot 2$ \\
\hline+28 & $440 \pm 27$ & $438 \pm 31$ & $34.9 \pm 1.6$ & $33.7 \pm 1 \cdot 1$ \\
\hline+42 & $447 \pm 29$ & $448 \pm 30$ & $35.0 \pm 1.8$ & $34 \cdot 3 \pm 1 \cdot 2$ \\
\hline+56 & $445 \pm 27$ & $450 \pm 28$ & $34.5 \pm 1.6$ & $33.7 \pm 1.0$ \\
\hline+68 & $457 \pm 27$ & $472 \pm 29$ & $34.9 \pm 1.2$ & $34 \cdot 3 \pm 1 \cdot 0$ \\
\hline
\end{tabular}

Values were similar $(P>0 \cdot 10)$ for control and oxytocin-treated bulls.

Oxytocin also was without effect $(P>0 \cdot 10)$ on scrotal circumference (Table 1). Scrotal circumference did not change significantly during the experiment for bulls of either treatment group $(P>0 \cdot 10)$. Since scrotal circumference is related to testicular weight, it was not surprising 
that oxytocin also was without effect on the weight of reproductive organs removed at castration (Table $2, P>0 \cdot 10$ ).

\section{Seminal characteristics and sperm output}

The volume of pre-sperm and sperm-rich fractions of first and second ejaculates was unaffected by the administration of oxytocin (Table $3, P>0 \cdot 10$ ). For each of these variables there were differences associated with collection day $(P<0.005)$. However, the variations appeared to be of a sporadic nature and, as for all seminal characteristics (i.e. seminal volume, sperm concentration and motility), treatment $\times$ time (i.e. collection day) interactions were non-significant $(P>0 \cdot 10)$. Similarly, oxytocin did not alter the sperm concentration of the pre-sperm or sperm-rich fractions of first ejaculates $(P>0.05)$ or of the pre-sperm fraction of second ejaculates (Table $3, P>0 \cdot 10)$. However, oxytocin reduced the sperm concentration within the sperm-rich fraction of second ejaculates (Table $3, P<0.01$ ).

The influence of oxytocin on the sperm concentration of second ejaculates was consistent with an effect of this hormone on sperm output. The total number of spermatozoa harvested per collection day was similar for control and oxytocin-treated bulls $(P>0 \cdot 10$, Table 3). Sperm output increased over time $(P<0.005)$, but the increase was similar $(P>0 \cdot 10)$ for bulls of both groups. For example, the number of spermatozoa harvested per collection day averaged 4.52 and $4.91 \times 10^{9}$ for control and oxytocin-treated bulls respectively during the 2-week pretreatment period, while corresponding means for the last 2 weeks of the experiment were 5.61 and $5.98 \times 10^{9}$, respectively. However, the administration of oxytocin caused a marked increase $(P<0.025)$ in the number of spermatozoa in first ejaculates and a corresponding decrease $(P<0.025)$ in the number within second ejaculates (Table 3). Of the total spermatozoa harvested per collection day, $47 \cdot 3$, $41 \cdot 3,43 \cdot 0,45 \cdot 5,41 \cdot 0$ and $45 \cdot 6 \%$ were obtained in the first ejaculates of control bulls during the pretreatment period and during each successive 2-week period of the study. In contrast, the corresponding percentages for oxytocin-treated bulls averaged $33 \cdot 2,56 \cdot 9,54 \cdot 1,62 \cdot 0,58 \cdot 3$ and $59 \cdot 2$, respectively. Although it is not clear why the relative sperm output in first and second ejaculates of bulls in the two groups differed during the pretreatment period, the percentage of the total spermatozoa present within first ejaculates quite consistently averaged about $43 \cdot 3 \%$ in controls and $58 \cdot 1 \%$ in oxytocin-treated bulls during the treatment period. This corresponds to a $34 \cdot 2 \%$ increase in the sperm output of first ejaculates due to oxytocin (i.e. $58 \cdot 1 / 43 \cdot 3 \times 100$ ).

\section{Spermatogenesis}

The sperm output of bulls maintained on a regular 6-times/week seminal collection schedule approaches sperm production (Amann et al., 1974). Therefore, the similarity of sperm output throughout the present experiment was indicative of an absence of an effect of oxytocin on spermatogenesis. Further direct evidence of this is presented in Table 4. Despite differences among pairs of bulls $(P<0.05)$, oxytocin was without effect $(P>0 \cdot 10)$ on the numbers of type A spermatogonia, preleptotene primary spermatocytes, pachytene primary spermatocytes or round step 8 spermatids per Stage VIII seminiferous tubular cross-section (Table 4). In addition, oxytocin was without effect $(P>0 \cdot 10)$ on daily sperm production per gram of testicular parenchyma, per testis or per bull, as judged by the numbers of homogenization-resistant elongated spermatids.

\section{Epididymal sperm reserves}

Since oxytocin did not alter rates of sperm production or total daily sperm output, it was not surprising that oxytocin was without effect on the epididymal sperm reserves within tissues removed at castration on Day $+68,1$ day after the last ejaculation (Table 5). Neither the total paired epididymal sperm reserves nor the distribution of spermatozoa within the proximal or distal epididymal segments were influenced by oxytocin administration $(P>0 \cdot 10)$. 
Table 2. Mean ( \pm s.e.) weight $(\mathrm{g})$ of reproductive organs from control and oxytocin-treated bulls at castration

\begin{tabular}{lrr}
\hline \multicolumn{1}{c}{ Organ } & \multicolumn{1}{c}{ Control } & \multicolumn{1}{c}{ Oxytocin } \\
\hline Paired testes & $521 \cdot 0 \pm 50 \cdot 9$ & $504 \cdot 2 \pm 33 \cdot 7$ \\
Testicular parenchyma & $469 \cdot 2 \pm 44 \cdot 5$ & $458 \cdot 4 \pm 29 \cdot 8$ \\
Paired epididymides & $53 \cdot 7 \pm 3 \cdot 7$ & $52 \cdot 9 \pm 4 \cdot 3$ \\
Proximal epididymis & $29 \cdot 0 \pm 2 \cdot 2$ & $27 \cdot 7 \pm 2 \cdot 1$ \\
Distal epididymis & $24 \cdot 7 \pm 1 \cdot 7$ & $25 \cdot 2 \pm 2 \cdot 4$ \\
\hline
\end{tabular}

Organ weights were similar $(P>0 \cdot 10)$ for control and oxytocin-treated bulls.

Table 3. Seminal characteristics (means \pm s.e.) of control and oxytocin-treated bulls during the pretreatment* and treatment† periods

\begin{tabular}{|c|c|c|c|c|}
\hline \multirow{2}{*}{$\begin{array}{c}\text { Seminal } \\
\text { characteristics }\end{array}$} & \multicolumn{2}{|c|}{ Control } & \multicolumn{2}{|c|}{ Oxytocin-treated } \\
\hline & 1st ejaculate & 2nd ejaculate & 1st ejaculate & 2nd ejaculate \\
\hline \multicolumn{5}{|l|}{ Pretreatment period $\ddagger$} \\
\hline Pre-sperm vol. (ml) & $3.9 \pm 0.7$ & $3.7 \pm 0.9$ & $3.7 \pm 0.4$ & $3.4 \pm 0.5$ \\
\hline Pre-sperm conc. $\left(\times 10^{-6}\right)$ & $48 \cdot 3 \pm 13 \cdot 2$ & $152.5 \pm 25.7$ & $95.4 \pm 24.9$ & $176 \cdot 2 \pm 69 \cdot 6$ \\
\hline Sperm-rich vol. (ml) & $5 \cdot 2 \pm 0.4$ & $8.4 \pm 0.6$ & $4.3 \pm 0.2$ & $7.1 \pm 0.6$ \\
\hline Sperm-rich conc. $\left(\times 10^{-6}\right)$ & $358.9 \pm 59.7$ & $243.8 \pm 27 \cdot 8$ & $327 \cdot 1 \pm 50 \cdot 7$ & $384 \cdot 8 \pm 23 \cdot 1$ \\
\hline \multicolumn{5}{|l|}{ Treatment period $\ddagger$} \\
\hline Pre-sperm vol. (ml) & $6 \cdot 1 \pm 0.2^{\mathrm{a}}$ & $6.6 \pm 0.4^{b}$ & $4 \cdot 6 \pm 0 \cdot 2^{\mathrm{a}}$ & $5 \cdot 4 \pm 0.2^{b}$ \\
\hline Pre-sperm conc. $\left(\times 10^{-6}\right)$ & $75 \cdot 8 \pm 8 \cdot 6^{\mathrm{a}}$ & $118 \cdot 2 \pm 11 \cdot 1^{b}$ & $174.9 \pm 17 \cdot 3^{\mathrm{a}}$ & $145 \cdot 5 \pm 8 \cdot 4^{b}$ \\
\hline Sperm-rich vol. (ml) & $5 \cdot 3 \pm 0.2^{a}$ & $7.7 \pm 0.3^{b}$ & $5.2 \pm 0.2^{\mathrm{a}}$ & $7 \cdot 2 \pm 0.3^{b}$ \\
\hline Sperm-rich conc. $\left(\times 10^{-6}\right)$ & $388 \cdot 1 \pm 21 \cdot 8^{a}$ & $366 \cdot 3 \pm 17 \cdot 7^{\mathrm{b}}$ & $184 \cdot 3 \pm 25 \cdot 4^{\mathrm{a}}$ & $252.9 \pm 11 \cdot 7^{\mathrm{c}}$ \\
\hline \multicolumn{5}{|c|}{ Total spermatozoa/ejaculate $\left(\times 10^{-9}\right)$} \\
\hline Weeks $-2+-1$ & $2 \cdot 14 \pm 0.41$ & $2.38 \pm 0.44$ & $1.63 \pm 0.15$ & $3 \cdot 28 \pm 0 \cdot 40$ \\
\hline Weeks $1+2$ & $2 \cdot 16 \pm 0.12^{\mathrm{d}}$ & $3.07 \pm 0.35^{f}$ & $2.85 \pm 0.39^{\mathrm{e}}$ & $2 \cdot 16 \pm 0 \cdot 16^{8}$ \\
\hline Weeks $3+4$ & $2.04 \pm 0.31^{\mathrm{d}}$ & $2 \cdot 70 \pm 0.38^{\mathrm{r}}$ & $3.01 \pm 0.39^{\mathrm{e}}$ & $2.55 \pm 0.18^{8}$ \\
\hline Weeks $5+6$ & $2.20 \pm 0.41^{\mathrm{d}}$ & $2.63 \pm 0.42^{\mathrm{f}}$ & $3.20 \pm 0.38^{e}$ & $1.96 \pm 0.17^{8}$ \\
\hline Weeks $7+8$ & $2.43 \pm 0.26^{\mathrm{d}}$ & $3.49 \pm 0.12^{\mathrm{f}}$ & $3.43 \pm 0.43^{\mathrm{e}}$ & $2.45 \pm 0.28^{\mathrm{g}}$ \\
\hline Weeks $9+10$ & $2.56 \pm 0.27^{\mathrm{d}}$ & $3.05 \pm 0.45^{\mathrm{f}}$ & $3.54 \pm 0.28^{e}$ & $2.44 \pm 0.21^{8}$ \\
\hline
\end{tabular}

*Weeks $-2+-1$.

†Weeks 1-10.

$\ddagger$ Standard errors among days.

${ }^{a}$ Means for first ejaculates were similar $(P>0.05)$ for control and oxytocin-treated bulls.

${ }^{b c}$ Means for second ejaculates that do not bear a similar superscript differ $(P<0.01)$.

${ }^{d e, f_{g}}$ Means for first $\left({ }^{\text {de }}\right)$ or second $\left({ }^{f_{\mathrm{g}}}\right)$ ejaculates that do not bear a similar superscript differ $(P<0.025)$.

\section{Seminal quality}

The percentage of progressively motile spermatozoa in fresh ejaculates is shown in Table 6. Oxytocin was without effect $(P>0 \cdot 10)$ on the motility of spermatozoa in first and second ejaculates. Also, oxytocin did not influence the percentage of progressively motile spermatozoa or the percentage of spermatozoa with intact acrosomes in frozen-thawed semen (Table $7, P>0 \cdot 10$ ). It was therefore concluded that oxcytocin did not influence sperm quality. 
Table 4. Spermatogenesis in control and oxytocin-treated bulls as judged by numbers of germ cells per stage VIII seminiferous tubular cross-section and via determination of daily sperm production (DSP) from numbers of homogenization-resistant elongated spermatids (means \pm s.e.)

\begin{tabular}{|c|c|c|}
\hline & \multicolumn{2}{|c|}{ Treatment } \\
\hline & Control & Oxytocin \\
\hline & \multicolumn{2}{|c|}{ Germ cells/tubular cross-section } \\
\hline Type A spermatogonia & $2 \cdot 2 \pm 0.3$ & $2 \cdot 0 \pm 0 \cdot 3$ \\
\hline Preleptotene spermatocytes & $20 \cdot 2 \pm 2 \cdot 0$ & $20 \cdot 1 \pm 1 \cdot 1$ \\
\hline Pachytene spermatocytes & $19 \cdot 2 \pm 2 \cdot 2$ & $19 \cdot 5 \pm 1 \cdot 2$ \\
\hline \multirow[t]{2}{*}{ Step 8 spermatids } & $71.5 \pm 9.2$ & $68.0 \pm 4.6$ \\
\hline & \multicolumn{2}{|c|}{ Daily sperm production } \\
\hline \multicolumn{3}{|l|}{$\mathrm{DSP} / \mathrm{g}\left(\times 10^{-6}\right)$} \\
\hline Left testis & $8 \cdot 90 \pm 1 \cdot 1$ & $9.66 \pm 0.5$ \\
\hline Right testis & $9 \cdot 71 \pm 1 \cdot 2$ & $9.54 \pm 0.7$ \\
\hline Mean & $9 \cdot 31 \pm 1 \cdot 1$ & $9 \cdot 60 \pm 0.5$ \\
\hline DSP/paired testes $\left(\times 10^{-9}\right)$ & $4.30 \pm 0.55$ & $4 \cdot 38 \pm 0.34$ \\
\hline DSP of left testis & $2.07 \pm 0.26$ & $2 \cdot 16 \pm 0.05$ \\
\hline DSP of right testis & $2.22 \pm 0.29$ & $2.22 \pm 0.18$ \\
\hline
\end{tabular}

Germ cell numbers and DSP were similar $(P>0 \cdot 10)$ for control and oxytocintreated bulls.

Table 5. Epididymal sperm reserves $\left(\times 10^{-9}\right)$ of control and oxytocin-treated bulls

\begin{tabular}{lrr}
\hline & \multicolumn{1}{c}{ Control } & \multicolumn{1}{c}{ Oxytocin } \\
\hline Paired proximal epididymides & $11.43 \pm 1.8$ & $12.09 \pm 1 \cdot 6$ \\
Left proximal & $5.55 \pm 1.0$ & $5.64 \pm 0.7$ \\
Right proximal & $5.88 \pm 0.9$ & $6.45 \pm 1 \cdot 0$ \\
Paired distal epididymides & $17 \cdot 16 \pm 2.4$ & $19.03 \pm 1 \cdot 6$ \\
$\quad$ Left distal & $8.93 \pm 1.4$ & $9.76 \pm 1 \cdot 1$ \\
$\quad$ Right distal & $8.23 \pm 1.2$ & $9.26 \pm 1 \cdot 1$ \\
Total paired epididymides & $28.59 \pm 4.0$ & $31.11 \pm 2.9$ \\
\hline
\end{tabular}

Values are mean \pm s.e.

All values for control and oxytocin-treated bulls are similar $(P>0 \cdot 10)$.

\section{Discussion}

The present investigation was designed to permit an evaluation of the effects of oxytocin, given before collection of first ejaculates, on spermatogenesis, sperm output and seminal quality of electroejaculated bulls. The frequency of electroejaculation (6 times/week) was adopted for two reasons. First, at such a frequency sperm output approaches sperm production. Thus, sperm output was available as one of three criteria for assessment of sperm production rates. In addition, since there is little reason to exceed such a frequency for bulls maintained for use in artificial insemination programmes, the oxytocin regimen used herein would probably constitute a maximal 
Table 6. Mean \pm s.e. percentage of progressively motile spermatozoa in ejaculates from control and oxytocin-treated bulls

\begin{tabular}{|c|c|c|c|c|}
\hline \multirow{2}{*}{$\begin{array}{c}\text { Time } \\
\text { period } \\
\text { (weeks) }\end{array}$} & \multicolumn{2}{|c|}{ Control } & \multicolumn{2}{|c|}{ Oxytocin } \\
\hline & $\begin{array}{c}\text { 1st } \\
\text { ejaculate }\end{array}$ & $\begin{array}{l}\text { 2nd } \\
\text { ejaculate }\end{array}$ & $\begin{array}{c}1 \text { st } \\
\text { ejaculate }\end{array}$ & $\begin{array}{l}\text { 2nd } \\
\text { ejaculate }\end{array}$ \\
\hline$-2 \&-1$ & $58 \cdot 8 \pm 1 \cdot 2$ & $62 \cdot 4 \pm 1 \cdot 1$ & $57 \cdot 5 \pm 1 \cdot 6$ & $64 \cdot 0 \pm 1 \cdot 2$ \\
\hline $1 \& 2$ & $55.5 \pm 1.4$ & $59.4 \pm 0.7$ & $57.5 \pm 0.7$ & $61 \cdot 1 \pm 1 \cdot 0$ \\
\hline $3 \&$ & $55.5 \pm 1.4$ & $59 \cdot 1 \pm 2 \cdot 3$ & $57.9 \pm 1.2$ & $58.5 \pm 2.4$ \\
\hline $5 \&$ & $56.1 \pm 1 \cdot 1$ & $61 \cdot 1 \pm 1 \cdot 4$ & $55.1 \pm 1.8$ & $58.1 \pm 1.9$ \\
\hline $7 \&$ & $57.6 \pm 1.7$ & $59.3 \pm 1 \cdot 3$ & $58.3 \pm 1.8$ & $61.3 \pm 1.9$ \\
\hline $9 \& 10$ & $55 \cdot 1 \pm 1.2$ & $60.3 \pm 1.5$ & $60.5 \pm 2.1$ & $64.8 \pm 1.0$ \\
\hline
\end{tabular}

All values for control and oxytocin-treated bulls are similar $(P>0 \cdot 10)$.

Table 7. Mean \pm s.e. post-thaw motility and acrosomal integrity of spermatozoa from control and oxytocin-treated bulls

\begin{tabular}{ccclcc}
\hline & \multicolumn{2}{c}{ Motility (\%) } & & \multicolumn{2}{c}{ Intact acrosomes (\%) } \\
\cline { 2 - 3 } \cline { 5 - 6 } Day & Control & Oxytocin & & Control & Oxytocin \\
\hline-5 & $30 \cdot 8 \pm 3 \cdot 6$ & $30 \cdot 7 \pm 4 \cdot 8$ & & $47 \cdot 0 \pm 1 \cdot 7$ & $48 \cdot 4 \pm 2 \cdot 4$ \\
+9 & $23 \cdot 2 \pm 3 \cdot 8$ & $29 \cdot 3 \pm 1 \cdot 9$ & & $51 \cdot 2 \pm 2 \cdot 5$ & $47 \cdot 2 \pm 2 \cdot 6$ \\
+23 & $25 \cdot 7 \pm 4 \cdot 6$ & $23 \cdot 6 \pm 3 \cdot 0$ & & $43 \cdot 8 \pm 2 \cdot 5$ & $44 \cdot 1 \pm 2 \cdot 1$ \\
+37 & $33 \cdot 6 \pm 3 \cdot 8$ & $30 \cdot 4 \pm 2 \cdot 7$ & & $48 \cdot 2 \pm 2 \cdot 3$ & $49 \cdot 6 \pm 2 \cdot 8$ \\
+51 & $25 \cdot 0 \pm 4 \cdot 8$ & $28 \cdot 9 \pm 3 \cdot 3$ & & $43 \cdot 7 \pm 1 \cdot 9$ & $48 \cdot 3 \pm 2 \cdot 2$ \\
+65 & $23 \cdot 6 \pm 5 \cdot 6$ & $36 \cdot 1 \pm 2 \cdot 2$ & & $51 \cdot 3 \pm 2 \cdot 2$ & $46 \cdot 2 \pm 2 \cdot 4$
\end{tabular}

All values are similar $(P>0 \cdot 10)$ for control and oxytocin-treated bulls.

dosage for the potential purpose of enhancing sperm output. The present results (Tables 2-4) constitute exceptionally strong evidence that oxytocin was without effect on spermatogenesis when given at the dosage and frequency employed herein. However, it was apparent $a$ priori that, if oxytocin enhanced sperm output, it could not sustain a prolonged increase in total daily sperm output, at such a frequency of ejaculation, unless spermatogenesis was enhanced. Therefore, if oxytocin enhanced sperm output during ejaculation without altering sperm production, one of two responses might be detected: (1) a short-term increase in sperm output during the early phase of the treatment period, caused by a lowering of epididymal sperm reserves. Such a response was not noted (Tables 3 and 5); and (2) more spermatozoa might be harvested in first ejaculates with a corresponding reduction in the number for second ejaculates. The latter could be anticipated because of the reduced number of epididymal spermatozoa available for ejaculation upon increased removal during the first ejaculate, and because of the relatively short half-life of the oxytocin response. It was clear that oxytocin did enhance sperm output of electroejaculated bulls (Table 3) and that the $34 \cdot 2 \%$ increase in first ejaculates was roughly comparable to the increase noted due to sexual preparation of bulls from which semen was collected with an artificial vagina (Hale \& Almquist, 1960; Almquist, 1973).

It is not known whether sperm output might be enhanced further by the administration of oxytocin before both ejaculates. However, in the absence of an effect on sperm production, it would 
seem that the use of oxytocin to enhance sperm output would be most advantageous for bulls electroejaculated less frequently and/or when the collection of only a single ejaculate was planned. By administering oxytocin, it might be possible to reduce the frequency of electroejaculation for bulls with certain physical disabilities, thereby reducing stress to the bull and the labour associated with collection and subsequent processing of semen, without compromising the number of inseminates available over time.

Ejaculates harvested by electroejaculation typically have a greater volume and lower sperm concentration than those obtained with an artificial vagina (Ball, 1974). The technique of the individual performing the electroejaculation can also influence these factors. Although the primary reason for recording seminal volume and sperm concentration was to permit calculation of sperm output, the former also provide some insight into the potential effects of oxytocin on accessory sex gland function. The absence of an effect of oxytocin on the volume of the pre-sperm or sperm-rich fractions of the first or second ejaculates $(P>0 \cdot 10)$ is consistent with the likely absence of an effect of oxytocin on the accessory sex glands of the bull. At the same time, oxytocin altered the number of spermatozoa in first and second ejaculates despite the general absence of effects on seminal volumes or sperm concentrations. The latter are quite variable and tend to change inversely in relation to one another. Accordingly, we suspect that the product of these two measures (i.e. sperm output) was less variable and/or was influenced to a greater extent by oxytocin than was either of these individual components, thus revealing statistically significant treatment effects on total sperm output.

Because most semen is frozen for use in artificial insemination programmes, the effects of oxytocin on post-thaw seminal quality were examined. The semen was frozen by a scheduled protocol and some samples were processed which would have been regarded as unacceptable for processing under most commercial artificial insemination programmes. For such reasons, the present results with frozen semen should be viewed as constituting a preliminary assessment only. While the results are not extensive, they provide no reason to suspect that oxytocin impaired the ability of spermatozoa to withstand freezing or thawing. This is consistent with the acceptability for freezing of semen obtained by collection methods known to elicit endogenous oxytocin secretion (Sharma et al., 1972). In contrast to these results, the motility of spermatozoa in fresh ejaculates was assessed by evaluation of approximately 1000 ejaculates during the 2 -week pre-treatment and 10 -week treatment periods. Given the size of this sample, the absence of an effect of oxytocin on motility $(P>0 \cdot 10)$ constitutes very strong evidence that oxytocin was without effect on this criterion. From the evidence presented herein, it is concluded that oxytocin did not alter the quality of semen obtained via electroejaculation of young dairy bulls.

Scientific contribution No. 1488 from the New Hampshire Agricultural Experiment Station. Supported in part by grants-in-aid from Eastern Artificial Insemination Cooperative, Inc. (Ithaca, New York), Select Sires (Plain City, Ohio), and American Breeders Service (DeForest, Wisconsin). We thank Clayton Penniman (Office of Biometrics) for statistical advice and Wendy Harding, David Anderson and Christopher Jacques for technical assistance.

\section{References}

Abercrombie, M. (1946) Estimation of nuclear population from microtome sections. Anat. Rec. 94, $239-247$.

Agmo, A., Andersson, R. \& Johansson, C. (1978) Effect of oxytocin on sperm numbers in spontaneous rat ejaculates. Biol. Reprod. 18, 346-349.

Almquist, J.O. (1973) Effects of sexual preparation on sperm output, semen characteristics and sexual activity of beef bulls with a comparison to dairy bulls. J. Anim. Sci. 36, 331-336.
Amann, R.P. \& Almquist, J.O. (1961a) Reproductive capacity of dairy bulls. I. Technique for direct measurement of gonadal and extragonadal sperm reserves. J. Dairy Sci.44, 1537-1543.

Amann, R.P. \& Almquist, J.O. (196Ib) Reproductive capacity of dairy bulls. V. Detection of testicular deficiencies and requirements for experimentally evaluating testis function from semen characteristics. J. Dairy Sci. 44, 2283-2291.

Amann, R.P., Kavanaugh, J.F., Griel, L.C., Jr, \& 
Voglmayr, J.K. (1974) Sperm production of Holstein bulls determined from testicular spermatid reserves, after cannulation of rete testis or vas deferens, and by daily ejaculation. J. Dairy Sci. 57, 93-99.

Ball, L. (1974) Electroejaculation of bulls. Proc. 5th N.A.A.B. Tech. Conf., A.I. \& Reprod. pp. 95-100.

Berndtson, W.E. (1977) Methods for quantifying mammalian spermatogenesis: a review. J. Anim. Sci. 44, 818-833.

Berndtson, W.E. \& Desjardins, C. (1974) The cycle of the seminiferous epithelium and spermatogenesis in the bovine testis. Am. J. Anat. 140, 167-180.

Berndtson, W.E., Chenoweth, P.J., Seidel, G.E., Jr, Pickett, B.W. \& Olar, T.T. (1979) Influence of prostaglandin $\mathrm{F}_{2 \alpha}$ on spermatogenesis, spermatozoal output, seminal quality, testosterone levels and libido of yearling beef bulls. J. Anim. Sci. 49, 736-742.

Berndtson, W.E., Igboeli, G. \& Parker, W.G. (1987) The numbers of Sertoli cells in mature Holstein bulls and their relationship to quantitative aspects of spermatogenesis. Biol. Reprod. 37, 60-67.

DeAbreu, R.M., Berndtson, W.E., Smith, R.L. \& Pickett, B.W. (1979) Effect of post-thaw warming on viability of bovine spermatozoa thawed at different rates in French straws. J. Dairy Sci. 62, 1449-1454.

Foote, R.H., Arriola, J. \& Wall, R.J. (1978) Principles and procedures for photometric measurement of sperm cell concentration. Proc. 7th N.A.A.B. Tech. Conf., A.I. \& Reprod. pp. 55-61.

Hale, E.B. \& Almquist, J.O. (1960) Relation of sexual behavior to germ cell output in farm animals. $J$. Dairy Sci. (April Suppl.) 43, 145-169.

Johnson, L., Berndtson, W.E. \& Pickett, B.W. (1976) An improved method for evaluating acrosomes of bovine spermatozoa. J. Anim. Sci. 42, 95I-954.

Kihlstrom, J.E. \& Melin, P. (1963) The influence of oxy- tocin upon some seminal characteristics in the rabbit. Acta physiol. Scand. 59, 363-369.

Knight, T.W. (1972) In vivo effects of oxytocin on the contractile activity of the cannulated epididymis and vas deferens in rams. J. Reprod. Fert. 28, 141, Abstr.

Knight, T.W. (1974a) The effect of oxytocin and adrenaline on the semen output of rams. J. Reprod. Fert. 39, 329-336.

Knight, T.W. (1974b) A qualitative study of factors affecting the contractions of the epididymis and ductus deferens of the ram. J. Reprod. Fert. 40, 19-29.

Knight, T.W. \& Lindsay, D.R. (1970) Short- and longterm effects of oxytocin on quality and quantity of semen from rams. J. Reprod. Fert. 21, 523-529.

Lino, B.F. (1971) Cell count correction factors for the quantitative histological analysis of the germinal epithelium of the ram. Anat. Rec. 170, 413-420.

Saacke, R.G. \& Marshall, C.E. (1968) Observations on the acrosomal cap of fixed and unfixed bovine spermatozoa. J. Reprod. Fert. 16, 511-514.

SAS Institute Inc. (1985) SAS User's Guide: Statistics, Version 5 Edition pp. 478-480. SAS, Cary.

Schefels, W. \& ElAzab, A. (1975) The effect of oxytocin on ejaculate composition in the bull. Theriogenology 4, 134, Abstr.

Sharma, O.P. \& Hays, R.L. (1973) Release of an oxytocic substance following genital stimulation in bulls. J. Reprod. Fert. 35, 359-362.

Sharma, S.C., Fitzpatrick, R.J. \& Ward, W.R. (1972) Coital-induced release of oxytocin in the ram. $J$. Reprod. Fert. 31, 488-489, Abstr.

Voglmayr, J.K. (1975) Output of spermatozoa and fluid by the testis of the ram and its response to oxytocin. J. Reprod. Fert. 43, 119-122.

Recieved 10 April 1987 